Article

\title{
Photomechanical Molecular Crystals of an Azopyridine Derivative and Its Zinc(II) Complex: Synthesis, Crystallization and Photoinduced Motion
}

\author{
Yanmei Guo ${ }^{1}$, Yunhui Hao ${ }^{1}$, Lei Gao ${ }^{1}$ and Hongxun Hao ${ }^{1,2, * \mathbb{D}}$ \\ 1 National Engineering Research Center of Industrial Crystallization Technology, School of Chemical \\ Engineering and Technology, Tianjin University, Tianjin 300072, China; gymgrace@163.com (Y.G.); \\ yunhuihao@tju.edu.cn (Y.H.); gracelei94@tju.edu.cn (L.G.) \\ 2 Collaborative Innovation Center of Chemical Science and Engineering (Tianjin), Tianjin 300072, China \\ * Correspondence: hongxunhao@tju.edu.cn; Tel.: +86-22-2740-5754; Fax: +86-22-2731-4971
}

Received: 13 January 2020; Accepted: 3 February 2020; Published: 6 February 2020

\begin{abstract}
In this work, photomechanical molecular crystals of 4-(4-(6-Hydroxyhexyloxy) phenylazo) pyridine (6cazpy) and its zinc(II) organic complex (complex-I) were synthesized and crystallized. DSC and TGA were used to characterize and compare properties of 6cazpy and its complex-I crystals. Photoinduced motions of 6cazpy crystals and its complex-I crystals were investigated and compared by UV/Vis irradiation. Bending away motions from the light source were observed from both 6cazpy crystals and its complex-I crystals. The bending away motion was attributed to the trans-to-cis photoisomerization of azopyridine derivatives in the crystalline phase. It is worth noting that the photomechanical properties of complex-I were enhanced by the formation of the ligand, which might be caused by the looser packing of molecules inside complex-I crystal. In addition, because of the existence of ligand, which combined two photoactive groups in each complex-I molecule, the isomerization reactions of these two photoactive groups in the molecules can increase the photomechanical movement ability of the crystal. It was also found that the crystal size and shape will affect the photoinduced movement of the crystals. PXRD and AFM were used to investigate the molecular mechanism and the surface topological change upon photoisomerization. The corresponding mechanism was proposed.
\end{abstract}

Keywords: azopyridine crystal; photomechanical behaviors; photoisomerization; bending

\section{Introduction}

Molecular actuators based on organic materials that change shape and/or size in response to external stimuli such as light [1-4], heat [5], $\mathrm{pH}$ value [6], electricity [7] or moisture [8] have shown their broad application prospects in medical devices, memory devices, artificial muscles and some other fields $[9,10]$. Among all the external stimuli, light which can be remotely, instantly and precisely controlled is an attractive source to adjust material properties. Therefore, many photomechanical materials such as azobenzene [11-15], salicylideneaniline [16], diarylethenes [17-19], anthracene [20,21], naphthalene diimides [22], furylfulgide [23] and even metal organic complex crystals [24,25] have been investigated for the realization of converting light energy to mechanical motion of bending [11,12], twisting [20,26,27], coiling [28,29], expanding [30], jumping [10] and popping [24].

Azobenzene compounds are typical chromophores that can undergo reversible trans to cis photoisomerization, resulting in rapid molecular geometry and size change. Azobenzene compounds have been widely investigated in the photoinduced motion filed. For example, Koshima et al. found that plate-like microcrystals of trans-4-aminoazobenzene quickly bent away from the light source 
and returned to their initial linear shape when irradiation was terminated [12]. Taniguchi et al. reported photomechanical bending processes accompanied with a twisting motion of chiral crystals of (S)-and(R)-N-[[4-p-dimethylaminophenylazo]benzoyl]-1-phenyl-thylamine [31].

In addition, scientists have made great efforts in the design and preparation of metal-organic compounds linked to light-controlling azobenzene molecules in recent years. They hope to produce fully functional photo-induced mechanical motions. Freixa et al. successfully synthesized the azobenzene-Pt complex in 2010 and found that the addition of Pt did not affect the photoisomerization and thermal stability of azobenzene and it was crucial for the potential application of catalysis [32].

Azopyridine derivatives show similar molecular structures with azobenzene compounds except that the carbon atom at the para-position in one benzene ring is replaced by a nitrogen atom. This small change in composition seldom affects the topological space, leading to similar photoisomerization of azopyridine derivatives in comparison to azobenzene compounds [33]. In addition, the introduction of the nitrogen atom enriches the properties of azopyridine derivatives with the possibility to self-assemble with halogen [34], inorganic acid [35], organic acid [36] and metal [37]. So far, investigations on azopyridine derivatives were mainly focused on the synthesis of polymer fibers [38], liquid-crystalline elastomers [36], photoresponsive liquid crystals [34] and luminescent complexes [37].

Compared with photoresponsive polymers, photomechanical molecular crystals show many advantages, such as faster response time [39], higher Young's modulus [40] and an ordered crystal structure [41]. However, little research about the photomechanical motion of molecular crystal of azopyridine and its application in photomechanical motion has been reported.

Zinc acetylacetonate is a heat stabilizer for halogenated polymers such as rigid PVC and has a significant synergistic effect with stearoyl benzoylmethane and dibenzoylmethane ( $\beta$-diketone) [42]. It can be used as a catalyst, resin crosslinking agent, resin hardening accelerator, resin and rubber additive, superconductive film, heat-reflecting glass film and the like [43-45]. In this work, considering the symmetrical structure, coordination ability and abundant applications of zinc acetylacetonate, a novel metal-organic complex crystal was synthesized from zinc acetylacetonate ligand and azopyridine derivative. Plate-like crystals of 4-(4-(6-Hydroxyhexyloxy) phenylazo) pyridine (6cazpy) (for molecular structure, see Scheme 1) were firstly synthesized and crystallized by the slow evaporation method. To combine the self-assembly properties of 6cazpy and zinc acetylacetonate, needle-like crystals of $\mathrm{Zn}$ (acetylacetonate) ${ }_{2}(6 \text { cazpy })_{2}$ (complex-I) were also synthesized and crystallized. The obtained crystals were characterized using DSC and TGA. The UV/Vis spectra of 6cazpy and complex-I in toluene solution at four irradiation conditions were also measured to explore the kinetics of photoisomerization of azopyridne molecules. Photomechanical motions of 6cazpy and its complex molecule crystals with different sizes were investigated and analyzed. Finally, PXRD and AFM data were used to investigate the molecular mechanism and surface topology change during photoisomerization.

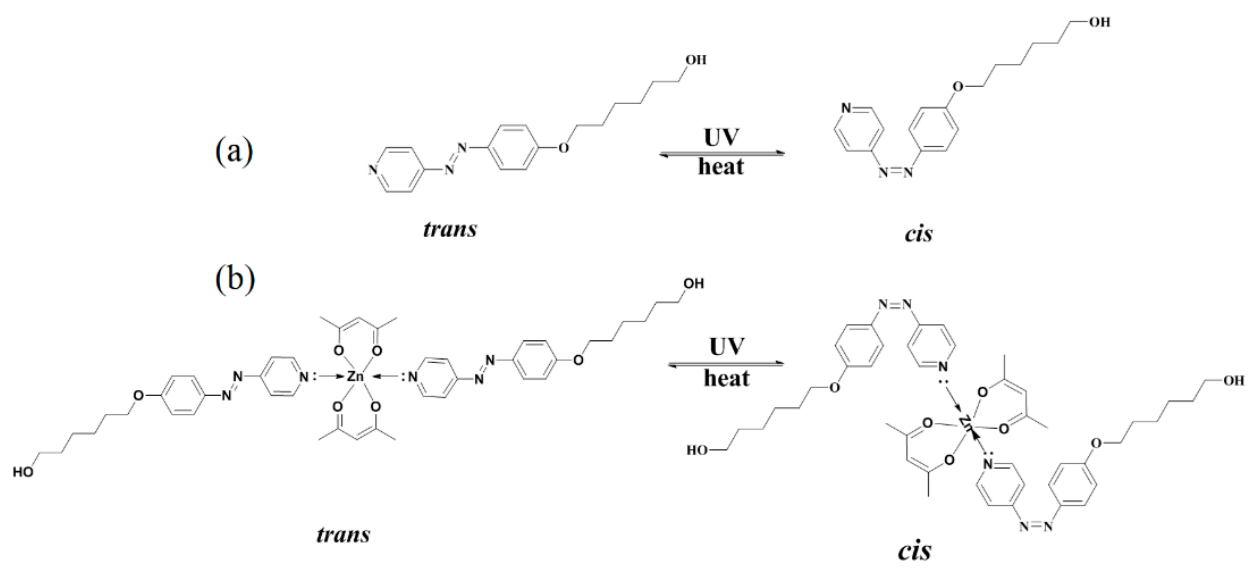

Scheme 1. Molecular structure and photoisomerization process of (a) 6cazpy and (b) complex-I. 


\section{Experimental Section}

\subsection{Materials}

4-aminopyridine, 6-chlorohexanol $\left(\mathrm{C}_{6} \mathrm{H}_{13} \mathrm{OCl}\right)$, hydrochloric acid $(\mathrm{HCl})$, sodium nitrite $\left(\mathrm{NaNO}_{2}\right)$, phenol, potassium carbonate $\left(\mathrm{K}_{2} \mathrm{CO}_{3}\right)$, potassium iodide $(\mathrm{KI})$, zinc acetylacetonate monohydrate ( $\left.\mathrm{Zn}(\mathrm{acac})_{2} \cdot \mathrm{H}_{2} \mathrm{O}\right)$, dimethylsulfoxide (DMSO), methanol and toluene were purchased from Tianjin Yixiang Chemical Co., Ltd. (Tianjin, China) and used as-received.

\subsection{Synthesis of 6cazpy}

6cazpy was synthesized as reported previously. ${ }^{34}$ The structural characterization results are as follows: ${ }^{1} \mathrm{H}$ NMR (Varian Medical Systems, California, USA) $\left(500 \mathrm{MHz}, 298 \mathrm{~K}, \mathrm{CDCl}_{3}\right): \delta=8.74-8.80$ (d, 2H, Ar-H), 7.93-7.98 (d, 2H, Ar-H), 7.66-7.70 (d, 2H, Ar-H), 6.99-7.05 (d, 2H, Ar-H), 4.03-4.10 $\left(\mathrm{t}, 2 \mathrm{H},-\mathrm{O}-\mathrm{CH}_{2}-\right), 3.65-3.71\left(\mathrm{t}, 2 \mathrm{H},-\mathrm{CH}_{2}-\right), 1.82-1.90\left(\mathrm{~m}, 2 \mathrm{H},-\mathrm{CH}_{2}-\right), 1.20-1.69\left(\mathrm{~m}, 6 \mathrm{H},-\mathrm{C}_{3} \mathrm{H}_{6}-\right)$ (see Supplementary Materials Figure S1). FTIR $\left(\mathrm{cm}^{-1}\right)$ (Bruker, Karlsruhe, Germany): $3273(-\mathrm{OH}), 2934$ $\left(-\mathrm{CH}_{2}\right), 2860\left(-\mathrm{CH}_{2}\right), 1592(-\mathrm{N}=\mathrm{N}-), 1498$ (-C=C-), 1452 (-C=C-), 1257 (-C-O-C-) (see Figure S2). The elemental analysis (\%): Calculated for $\mathrm{C}_{17} \mathrm{H}_{21} \mathrm{O}_{2} \mathrm{~N}_{3}$ : C 68.22, H 7.02, N 14.04; found: $\mathrm{C} 67.89, \mathrm{H}$ 7.32, N 14.28 .

\subsection{Preparation of 6cazpy and Complex-I Crystals}

Yellow plate-like crystals of 6cazpy were obtained by slow evaporation of solutions of compounds in methanol. 6cazpy $(0.287 \mathrm{~g}, 0.96 \mathrm{mmol})$ was added into a $50 \mathrm{~mL}$ crystallizer with $30 \mathrm{~mL}$ methanol. The solution was heated to $323 \mathrm{~K}$ by a thermostat (Julabo, Seelbach, Germany) and agitated by a magnetic stirrer (JHS-2190, Hangzhou, China) at $400 \mathrm{rpm}$ for about $30 \mathrm{~min}$. Then, the solution was filtered immediately. The obtained clear solution was transferred into a beaker sealed with parafilm. Then, the solution was slowly evaporated at room temperature. Five days later, plate-like crystals of 6cazpy were obtained at the bottom of the beaker. Complex-I crystals were synthesized and crystallized by the slow evaporation method. 6cazpy $(0.275 \mathrm{~g}, 0.92 \mathrm{mmol})$ and $\mathrm{Zn}(\mathrm{acac})_{2} \cdot \mathrm{H}_{2} \mathrm{O}(0.138 \mathrm{~g}, 0.49 \mathrm{mmol})$ were added into a $50 \mathrm{~mL}$ crystallizer with $30 \mathrm{~mL}$ toluene. The solution was heated to $323 \mathrm{~K}$ by a thermostat (Julabo, Seelbach, Germany) and agitated by a magnetic stirrer at $400 \mathrm{rpm}$ for about $2 \mathrm{~h}$ for complete reaction. Then, the mixture was cooled to $283 \mathrm{~K}$ and the agitation was stopped. The mixture was filtered immediately. The obtained clear solution was transferred into a beaker sealed with parafilm with a few holes. Then, the beaker with solution was put into a dryer (with constant temperature of $283 \mathrm{~K}$ ). Two weeks later, orange-red needle-like crystals of complex-I crystals were obtained at the bottom of the beaker. The structural characterization results are as follows: ${ }^{1} \mathrm{H} \mathrm{NMR}(500 \mathrm{MHz}$, $\left.298 \mathrm{~K}, \mathrm{CDCl}_{3}\right): \delta=8.70-8.80(\mathrm{~d}, 4 \mathrm{H}, \mathrm{Ar}-\mathrm{H}), 7.91-8.06(\mathrm{~d}, 4 \mathrm{H}, \mathrm{Ar}-\mathrm{H}), 7.70-7.77(\mathrm{~d}, 4 \mathrm{H}, \mathrm{Ar}-\mathrm{H}), 7.00-7.06$ $(\mathrm{d}, 4 \mathrm{H}, \mathrm{Ar}-\mathrm{H}), 5.40(\mathrm{~s}, 12 \mathrm{H}), 4.06-4.11(\mathrm{t}, 4 \mathrm{H}), 3.67-3.72(\mathrm{~m}, 4 \mathrm{H}), 1.82-1.94(\mathrm{~m}, 4 \mathrm{H}), 1.40-1.69(\mathrm{~m}, 12 \mathrm{H})$ (see Figure S3). FTIR $\left(\mathrm{cm}^{-1}\right): 3342(-\mathrm{OH}), 2921\left(-\mathrm{CH}_{2}-\right), 2851\left(-\mathrm{CH}_{2}-\right), 1577(-\mathrm{N}=\mathrm{N}-), 1513(-\mathrm{C}=\mathrm{C}-), 1450$ $(-\mathrm{C}=\mathrm{C}-), 1246$ (-C-O-C-), (see Figure S4). The elemental analysis (\%): calculated for $\mathrm{C}_{44} \mathrm{H}_{56} \mathrm{~N}_{6} \mathrm{O}_{8} \mathrm{Zn}$ : C 61.23, H 6.49, N 9.74; found: C 61.18, H 6.22, N 9.57.

\subsection{Characterization}

${ }^{1} \mathrm{H}$ NMR spectra were recorded in chloroform-d $\left(\mathrm{CDCl}_{3}\right)$ solution on a Bruker $500 \mathrm{MHz}$ spectrometer (Varian Medical Systems, Palo Alto, CA, USA) to confirm the molecular structure of the synthesized 6cazpy and complex-I. Elemental analyses were performed on a vario EL CUBE element analyzer (elementar, Heraeus, Germany). FTIR spectra were recorded on an ALPHA II FTIR Spectrometer (Bruker, Karlsruhe, Germany). The thermal properties were determined by differential scanning calorimetry (DSC) (NETZSCH, Serb, Germany) and a thermal gravimetric analyzer (TGA) (Mettler Toledo, Co., Zurich, Switzerland). During measurements, the heating rates were set at $5 \mathrm{~K} / \mathrm{min}$ and $10 \mathrm{~K} / \mathrm{min}$, respectively. UV-Vis absorption spectra of solutions were measured by UV-3010 spectrophotometer (HITACHI, Tokyo, Japan) with a $2 \mathrm{~cm}$ path length cell. 
Photomechanical motions upon UV-light irradiation were investigated with a high-speed digital microscope (Stereomicroscope“Stemi"508 Carl Zeiss, Jena, Germany). Irradiation was performed by using an UV-LED lamp (HTLD-4,365 nm, Shenzhen, China). Powder X-ray diffraction (PXRD) was performed using Rigaku D/MAX 2500 (Rigaku Corporation, Tokyo, Japan) with a scintillation counter. Atomic force microscopy (AFM) of samples was measured by a scanning probe microscope in tapping mode (Nanoscope V, Bruker, Karlsruhe, Germany).

\section{Results and Discussion}

\subsection{Crystal Morphology and Thermal Stability}

As shown in Figure 1, the prepared 6cazpy crystals exhibit bright yellow color and plate-like shape, while the complex-I crystals exhibit red color and needle-like shape. DSC and TGA data of these two kinds of crystals are shown in Figure 2. It can be seen that 6cazpy crystals started to melt at $391.5 \mathrm{~K}$ and decomposed at $538.3 \mathrm{~K}$ (Figure 2a,b). As for complex-I crystals, the melting and decomposition points are $368.2 \mathrm{~K}$ and $428.0 \mathrm{~K}$ (Figure 2c,d), respectively, both of which are lower than those of 6cazpy crystals. It suggests that both of the intermolecular interaction and intramolecular interaction in 6cazpy crystals are stronger than that in complex-I crystals.

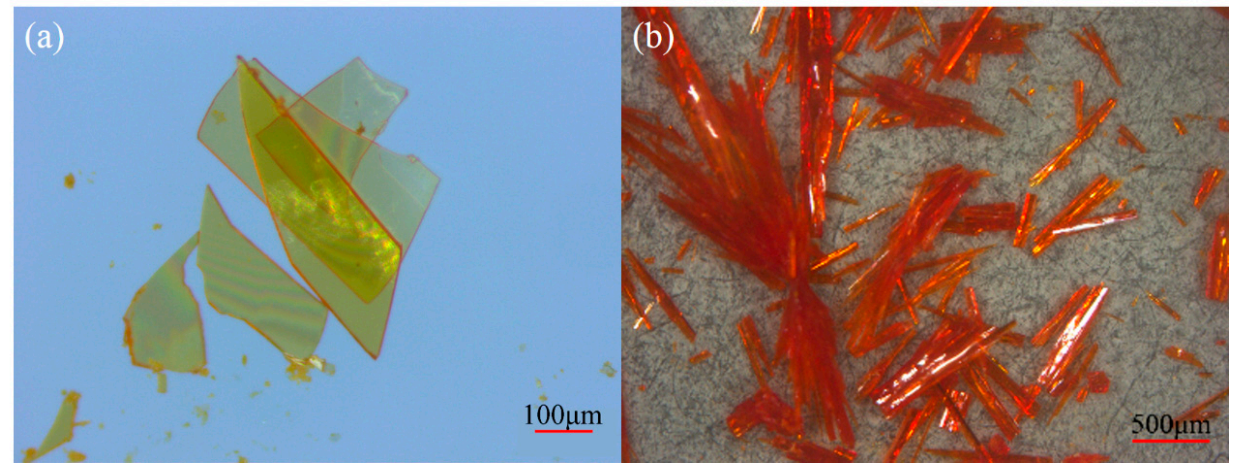

Figure 1. Optical microscope images of (a) plate-like 6cazpy crystals and (b) needle-like complex-I crystals.

(a)

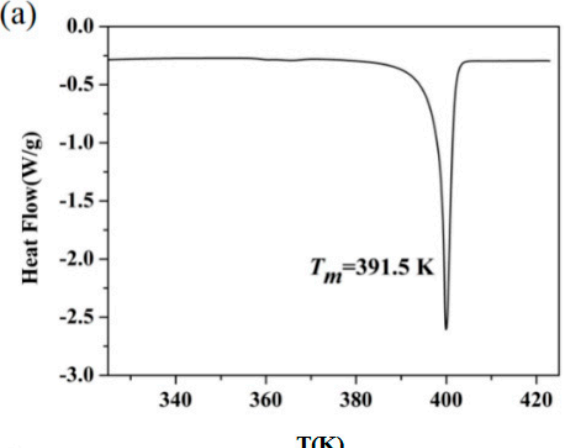

(c)

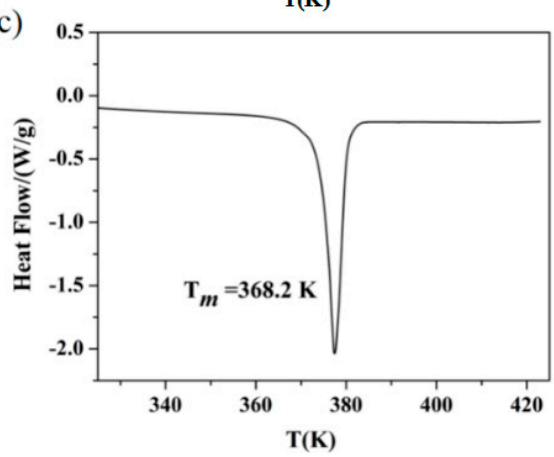

(b)

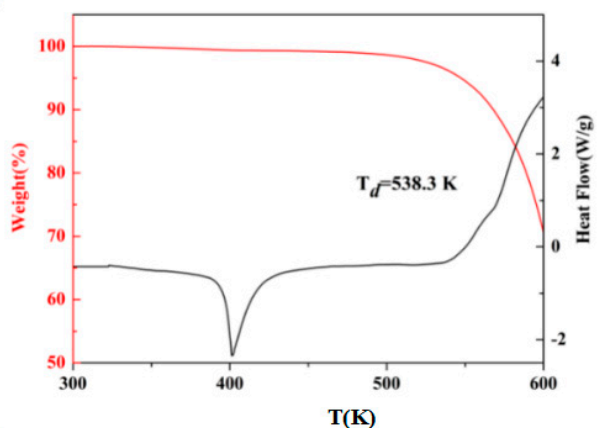

(d)



Figure 2. DSC and TGA plots of (a,b) 6cazpy crystals and (c,d) complex-I crystals. 


\subsection{UV/Vis Absorption Spectra}

UV-Vis spectra were used to study the photoresponsive properties of 6cazpy and complex-I. These two compounds were dissolved in toluene, respectively, and the solution concentration are controlled at $10^{-5} \mathrm{~mol} / \mathrm{L}$. The measurements were conducted at room temperature under four different conditions: (1) upon UV light $\left(\lambda=365 \mathrm{~nm}, 60 \mathrm{~mW} / \mathrm{cm}^{2}\right)$ irradiation with different irradiating times, (2) upon UV light $(\lambda=365 \mathrm{~nm}, \mathrm{t}=1 \mathrm{~s})$ irradiation using different intensities, (3) upon visible light $\left(\lambda=530 \mathrm{~nm}, 100 \mathrm{~mW} / \mathrm{cm}^{2}\right)$ irradiation with different irradiating times after the $600 \mathrm{~mW} / \mathrm{cm}^{2} \mathrm{UV}$ light irradiation, (4) upon visible light $(\lambda=530 \mathrm{~nm}, \mathrm{t}=4 \mathrm{~s})$ irradiation with different intensities after the $600 \mathrm{~mW} / \mathrm{cm}^{2} \mathrm{UV}$ light irradiation. When crystals of complex-I were dissolved into the solvent, the photoactive compounds were also 6cazpy molecules. Hence, the UV/Vis spectra (Figure 3) of 6cazpy and complex-I (see Figure S5 in SI) show similar phenomena. Here, only the results of 6cazpy are presented. As shown in Figure 3a,c, before the irradiation of $365 \mathrm{~nm}$ UV light, the maximum absorption peak at $356 \mathrm{~nm}$ was clearly observed, which was attributed to the $\pi-\pi^{*}$ transition of trans 6cazpy molecules. With the increasing of irradiation time and intensity of UV light, the absorbance of $\pi-\pi^{*}$ transition peak of 6cazpy in toluene solution at around $356 \mathrm{~nm}$ decreased and the peak blue-shifted to $320 \mathrm{~nm}$. Meanwhile, the absorption peak at about $440 \mathrm{~nm}$ slightly increased due to the $\mathrm{n}-\pi^{*}$ transition of cis 6cazpy molecules. This phenomenon was ascribed to trans to cis photoismerization and the steady state was reached after $10 \mathrm{~s}$ when the irradiation intensity was $60 \mathrm{~mW} / \mathrm{cm}^{2}$ or after $1 \mathrm{~s}$ when the irradiation intensity was $600 \mathrm{~mW} / \mathrm{cm}^{2}$. As shown in Figure $3 b, \mathrm{~d}$, when the solution was irradiated by $600 \mathrm{~mW} / \mathrm{cm}^{2} \mathrm{UV}$ light for $10 \mathrm{~s}$, the UV light was turned off and visible light $(\lambda=530 \mathrm{~nm})$ was used to irradiate the solution to test the reversibility of 6cazpy and complex-I in solution. It can be found that the absorption peak slightly shifted to the original position ( $356 \mathrm{~nm}$ ) and the peak at $440 \mathrm{~nm}$ gradually disappeared. It is worth noting that the photostationary state was achieved after $20 \mathrm{~s}$ when the irradiation intensity of visible light was $100 \mathrm{~mW} / \mathrm{cm}^{2}$ or after $4 \mathrm{~s}$ when the irradiation intensity of visible light was $500 \mathrm{~mW} / \mathrm{cm}^{2}$. In addition, the kinetics of the photoinduced isomerization were investigated. The isomerization kinetics results of 6cazpy and complex-I are shown in Figure 3e-h and Figure S5e-h in the Supplementary Information (SI), respectively. It can be found that the change of absorbance peak ( $\Delta$ (Absorbance peak $)$ ) exponentially increased with exposure time or light intensity. The relationship can be represented by the following equation,

$$
y=A(1-\exp (-k x))
$$

where $x$ represents the exposure time or light intensity, $y$ is the change of absorbance peak, $k$ is the rate constant and $A$ is the change of absorbance peak at photostationary state. According to Beer-Lambert law, the change of absorbance peak $(\Delta$ (Absorbance peak $))$ is proportional to the percentage of $c$ is or trans isomers in solution. Therefore, it can be inferred that the photoisomerization from trans to cis and cis to trans follows first-order kinetics. Parameters of Equation (1) were obtained by fitting the experimental values by using Origin software and the results are shown in Table 1. As the results of rate constants showed in Table 1, rates of photoisomerization from trans to cis are higher than that from cis to trans, which means that the reaction of trans to cis is faster than the reaction of cis to trans in solution. 
(a)

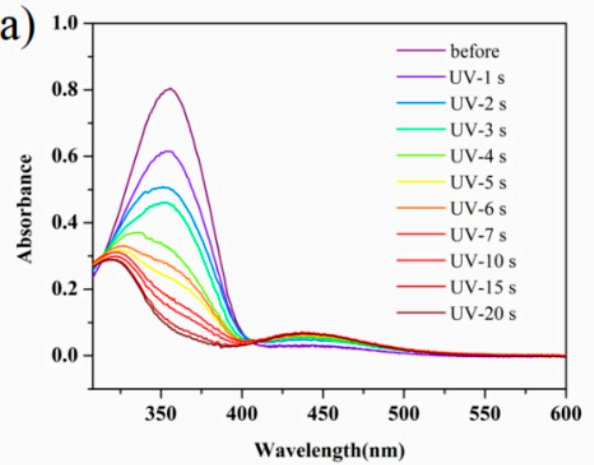

(c)

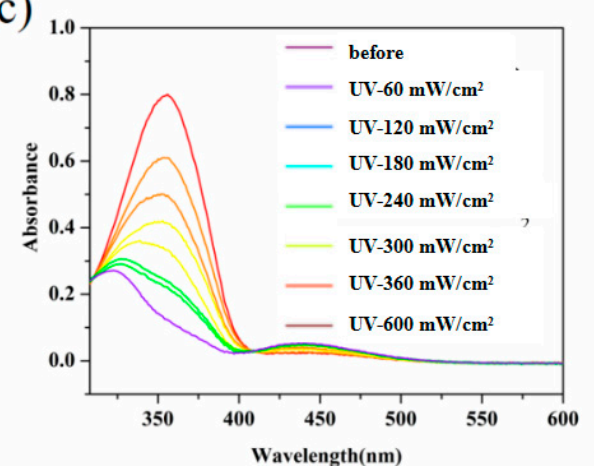

(e)



(g)

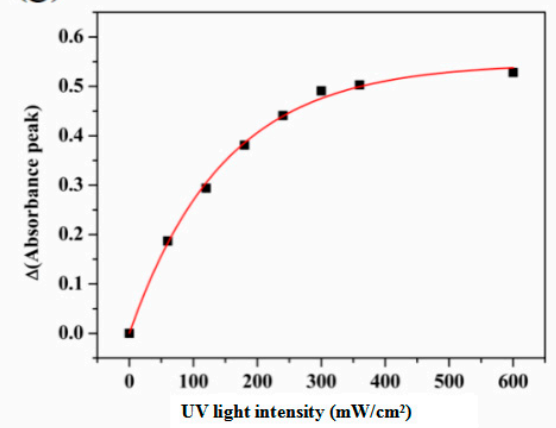

(b)

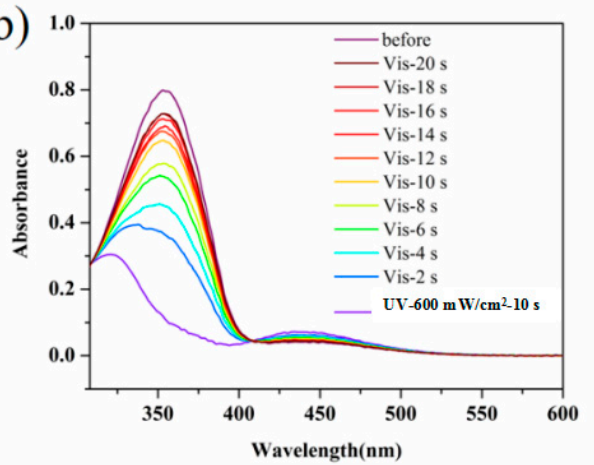

(d)

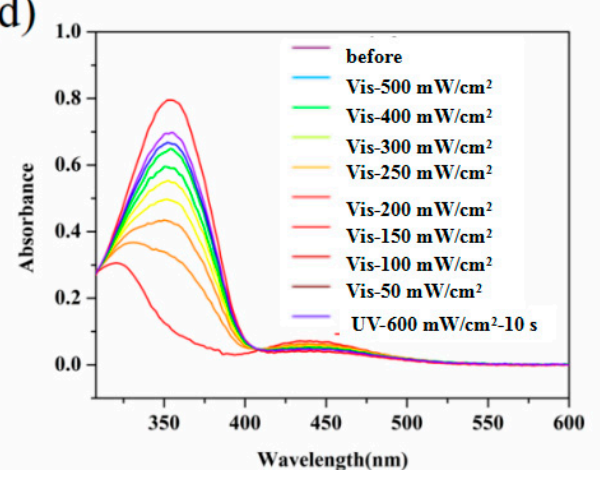

(f)



(h)

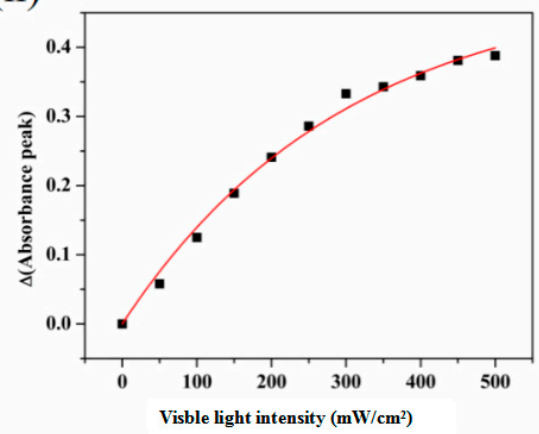

Figure 3. (a-d) UV/V is absorption spectra of 6cazpy in toluene at room temperature. (e-h) plots of change of absorbance peak ( $\Delta$ (Absorbance peak)) with time or light intensity. In each sample, the spectra (a,e) obtained upon UV light $\left(\lambda=365 \mathrm{~nm}, 60 \mathrm{~mW} / \mathrm{cm}^{2}\right)$ irradiation with different irradiating time, $(\mathbf{b}, \mathbf{f})$ obtained upon visible light $\left(\lambda=530 \mathrm{~nm}, 100 \mathrm{~mW} / \mathrm{cm}^{2}\right)$ irradiation with different irradiating time after the $600 \mathrm{~mW} / \mathrm{cm}^{2}$ UV light irradiation, (c,g) obtained upon UV light $(\lambda=365 \mathrm{~nm}, \mathrm{t}=1 \mathrm{~s})$ irradiation using different intensity, $(\mathbf{d}, \mathbf{h})$ obtained upon irradiation with visible light $(\lambda=530 \mathrm{~nm}$, $\mathrm{t}=4 \mathrm{~s}$ ) using different intensity after the $600 \mathrm{~mW} / \mathrm{cm}^{2} \mathrm{UV}$ light irradiation. 
Table 1. The parameters of Equation (1) in different irradiation conditions when measuring the UV/Vis spectra.

\begin{tabular}{cccc}
\hline Condition & $\boldsymbol{k}^{\boldsymbol{a}}$ & $\boldsymbol{A}^{\boldsymbol{a}}$ & $\mathbf{R}^{\mathbf{b}}$ \\
\hline $60 \mathrm{~mW} / \mathrm{cm}^{2}$ with different time (UV, 6cazpy) & $0.4267 \mathrm{~s}^{-1}$ & 0.5179 & 0.9929 \\
$100 \mathrm{~mW} / \mathrm{cm}^{2}$ with different time (Vis, 6cazpy) & $0.1059 \mathrm{~s}^{-1}$ & 0.4806 & 0.9937 \\
$1 \mathrm{~s}$ with different light intensity (UV, 6cazpy) & $0.0067\left(\mathrm{~mW} / \mathrm{cm}^{2}\right)^{-1}$ & 0.5469 & 0.9975 \\
4 s with different light intensity (Vis, 6cazpy) & $0.0030\left(\mathrm{~mW} / \mathrm{cm}^{2}\right)^{-1}$ & 0.4910 & 0.9925 \\
$60 \mathrm{~mW} / \mathrm{cm}^{2}$ with different time (UV, complex-I) & $0.2370 \mathrm{~s}^{-1}$ & 0.5190 & 0.9426 \\
$100 \mathrm{~mW} / \mathrm{cm}^{2}$ with different time (Vis, complex-I) & $0.0681 \mathrm{~s}^{-1}$ & 0.6083 & 0.9851 \\
1 s with different light intensity (UV, complex-I) & $0.0046\left(\mathrm{~mW} / \mathrm{cm}^{2}\right)^{-1}$ & 0.5688 & 0.9611 \\
4 s with different light intensity (Vis, complex-I) & $0.0036\left(\mathrm{~mW} / \mathrm{cm}^{2}\right)^{-1}$ & 0.4738 & 0.9932 \\
\hline
\end{tabular}

${ }^{a} k$ and $A$ are the parameters of Equation $(1) \cdot{ }^{b} \mathrm{R}^{2}$ represents the goodness of fit.

\subsection{Photoinduced Motion}

The above UV/Vis spectra results indicated that the molecules of 6cazpy and complex-I can undergo a reversible photoisomerization reaction. It means that the molecule crystals of 6cazpy and its complex-I will be potential photomechanical materials. Therefore, the photomechanical motions of crystalline 6cazpy and complex-I were investigated. Plate-like crystals of 6cazpy were obtained by slow evaporation of solutions of compounds in methanol in a few days at room temperature. Figure 4 shows the morphology of one plate-like microcrystal $(1592 \mu \mathrm{m} \times 746 \mu \mathrm{m} \times 2 \mu \mathrm{m})$ of 6 cazpy. The left position of the crystal was fixed on the glass surface and the right was free. The crystal was irradiated by $365 \mathrm{~nm}$ UV light $\left(480 \mathrm{~mW} / \mathrm{cm}^{2}\right)$ with a UV-LED from the right front, as indicated in Figure 4. The photomechanical motion of the crystal was observed by a microscope and recorded by a high-speed digital camera. When the crystal was irradiated by UV light, the crystal quickly bent away from the light source, reaching a maximum tip displacement of $60 \mu \mathrm{m}$ after $1 \mathrm{~s}$ (see Figure 4 and see Supplementary Materials Video S1), and longer time irradiation did not cause any further shape change. When the UV light was stopped, the crystal returned to its original shape immediately. The photomechanical motion of this crystal was observed over at least 120 cycles with alternating UV irradiation ( $3 \mathrm{~s}$ on, $2 \mathrm{~s}$ off).
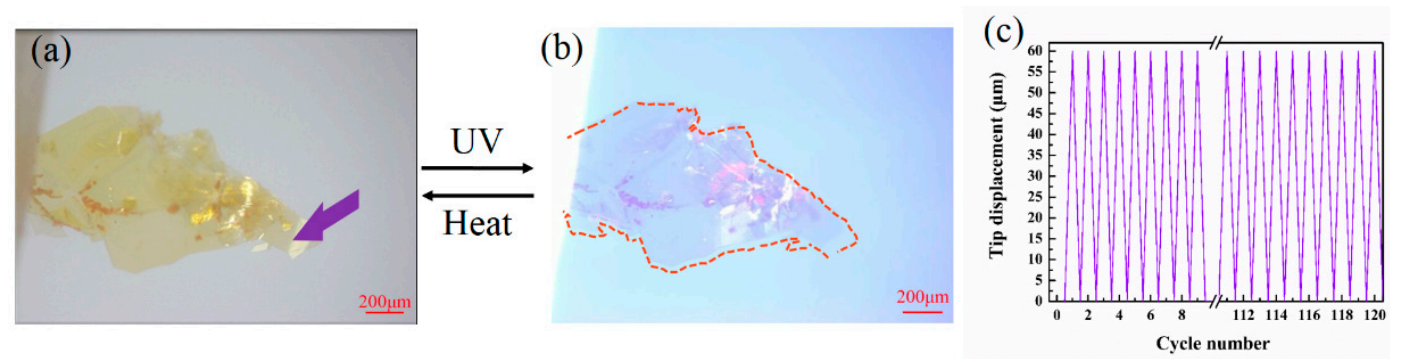

Figure 4. Photoinduced reversible bending of the plate-like 6cazpy crystal $(1592 \mu \mathrm{m} \times 746 \mu \mathrm{m} \times 2 \mu \mathrm{m})$ at room temperature. (a) Before and (b) after $365 \mathrm{~nm} \mathrm{UV} \mathrm{irradiation}\left(480 \mathrm{~mW} / \mathrm{cm}^{2}\right)$ and the red dashed line is the original position of crystal. UV irradiation was carried out from right front on the image (indicated by the purple arrow). (c) Graph shows the repeatability of the reversible bending with as many as 120 cycles.

The photomechanical motion of an irregular plate-like crystal $(1446 \mu \mathrm{m} \times 388 \mu \mathrm{m} \times 5 \mu \mathrm{m})$ of 6 cazpy was also tested. When the crystal was irradiated from the bottom-left with an irradiating intensity of $480 \mathrm{~mW} / \mathrm{cm}^{2}$ of $365 \mathrm{~nm}$ UV light, the crystal bent away from the light source and the maximum tip distance of $33.3 \mu \mathrm{m}$ was reached in $0.25 \mathrm{~s}$ (see Figure 5 and Video S2). The crystal went back to the original position immediately when the light was stopped. 


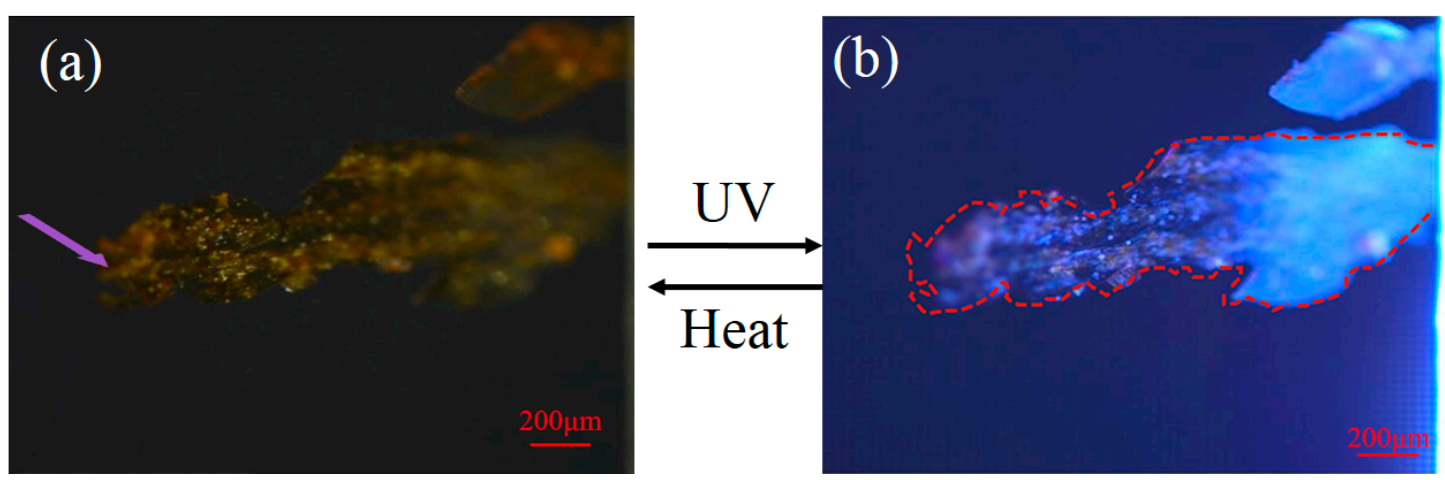

Figure 5. Photoinduced bending of a plate-like crystal (1446 $\mu \mathrm{m} \times 388 \mu \mathrm{m} \times 5 \mu \mathrm{m})$ of 6 cazpy (a) before and (b) after UV irradiation from the bottom-left side (indicated by the purple arrow) and the red dashed line is the original position of crystal.

A narrow and thicker plate-like microcrystal of 6cazpy $(1499 \mu \mathrm{m} \times 337 \mu \mathrm{m} \times 10 \mu \mathrm{m})$ with the lower end fixed on the glass surface and the upper end free was used to confirm the photomechanical motion (Figure 6). When subjected to UV irradiation $\left(480 \mathrm{~mW} / \mathrm{cm}^{2}\right)$ from up front, the crystal rapidly bent in the opposite direction of the light source, reaching a maximum tip displacement of $10 \mu \mathrm{m}$ after $0.2 \mathrm{~s}$ (see Video S3) and longer irradiation time did not cause any further shape change. When the UV light was stopped, the slightly bent crystal returned to its original shape immediately. When the UV light intensity was increased to $600 \mathrm{~mW} / \mathrm{cm}^{2}$, the maximum tip displacement increased to a longer distance of $20 \mu \mathrm{m}$ after $0.2 \mathrm{~s}$ (see Figure 6 and Video S4). The above phenomena indicate that the plate-like 6cazpy crystals can realize reversible photoinduced bending in a macroscopic range. The crystal size and irradiation intensity will affect the maximum displacement distance of the photoinduced motion of the crystals. The thicker the crystal is, the more difficult it is to observe the photomechanical motion. In particular, for some crystals with large bending inertia, no photomechanical motion can be observed at all [46]. This phenomena can be used to manipulate the photomechanical motion of the crystals in the real application.

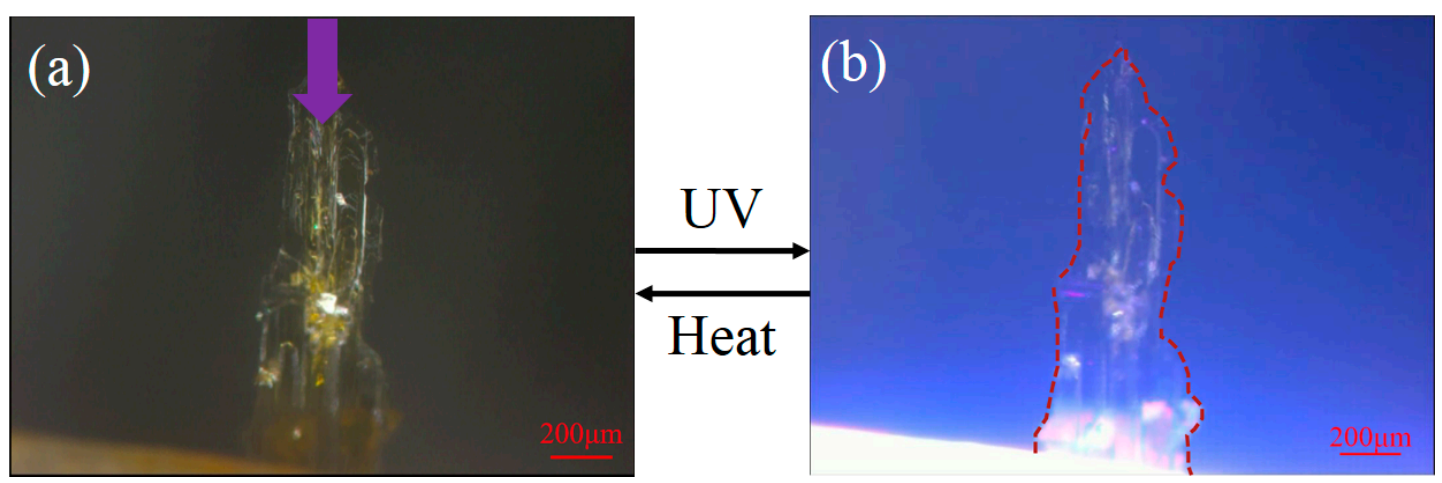

Figure 6. Photomechanical motion of plate-like crystal $(1499 \mu \mathrm{m} \times 337 \mu \mathrm{m} \times 10 \mu \mathrm{m})$ of 6cazpy: (a) Before and (b) after UV irradiation from up-front on the image (indicated by the purple arrow) and the red dashed line is the original position of crystal.

As for complex-I crystals, photoinduced bending can also be observed even when the crystal thickness is $44 \mu \mathrm{m}$ (thicker than the crystal of 6cazpy). This is shown in Figure 7 by comparing the microscope images of a needle-like crystal of complex-I $(3631 \mu \mathrm{m} \times 159 \mu \mathrm{m} \times 44 \mu \mathrm{m})$ before and after UV irradiation $\left(600 \mathrm{~mW} / \mathrm{cm}^{2}\right)$. It can be seen that the thick crystal bent to the opposite direction of the light source (at the right side) and reached a maximum displacement of $22 \mu \mathrm{m}$ after $0.25 \mathrm{~s}$ (for more information, see Video S5). The bent crystal returned to its original position immediately after the UV light was stopped. The repeatability of the reversible bending is as many as 120 cycles. 
Compared with 6cazpy, the thicker crystal of complex-I showed a similar tip displacement distance with a thinner crystal of 6cazpy $(20 \mu \mathrm{m})$ through photoisomerization in internal molecules. It was suggested that the motion of the photoactive molecules is less restricted in complex-I and the molecules can isomerize more easily than in the 6cazpy crystal structure. This is consistent with the thermal stability measurements, which indicate a lower melting point $(368.2 \mathrm{~K})$ for complex-I in comparison to 6cazpy (391.5 K). In addition, from the molecular structure of complex-I, it can be seen that the structure of acetylacetone in the ligand is symmetrical, which can provide greater room for isomerization. Each complex-I molecule in the crystal has two photoactive groups at the same time and when the isomerization reaction occurs, movements of two molecules will increase the deformation at the molecular level. Therefore, thicker crystals show larger tip displacements.
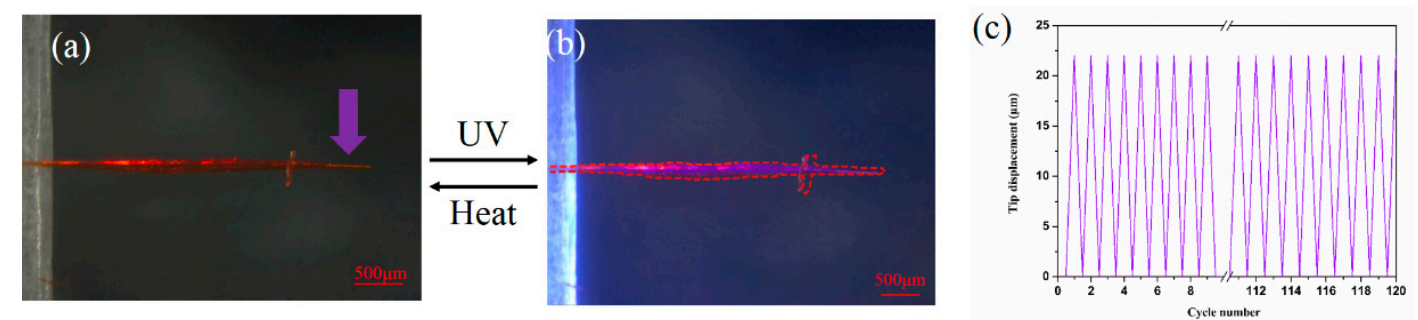

Figure 7. Photomechanical motion of a needle-like complex-I crystal at room temperature: (a) before and (b) after UV irradiation from the right above on the image (indicated by the purple arrow) and the red dashed line is the original position of crystal. (c) Graph shows the repeatability of the reversible bending over as many as 120 cycles.

Overall, while the thermostability of complex-I was a little lower, the tip displacement distance of complex-I was longer than 6cazpy, indicating that the ability of photomechanical motion of complex-I crystals is stronger and can be a promising molecule actuator.

\subsection{Mechanism of Photoinduced Motion}

Photomechanical motion of photoisomerization materials is known to be resulted from the molecular geometric deformation and photoinduced bending is commonly assumed to be induced by the strains that arise at the interface of the reactant-product bilayer [47]. When the UV light traverses a photomechanical crystal, the penetration distance of the UV light is limited. Therefore, generally, only molecules close to the surface of the crystal can undergo photoisomerization. The difference in stress between reactant-product regions provides the energy to actuate the visible deformation of the crystal (Figure $8 \mathrm{~b}$ ). To validate this hypothesis, PXRD was used to investigate the structure change in crystal and AFM was performed to show the surface topological change of the crystal surface upon UV irradiation for both 6cazpy and complex-I. PXRD patterns of crystals before, during and after UV-light irradiation are shown in Figure 9. When 6cazpy crystals were irradiated, the intensities of some peaks decreased. For example, the intensity of the peak at $2 \theta=4.782^{\circ}$ decreased to $50.6 \%$ of the original value (Figure $9 \mathrm{a}, \mathrm{b}$ ), likely due to the trans-to-cis photoisomerization and a corresponding deterioration of crystallinity [21]. The intensity eventually recovered to $64.6 \%$ of the original value at $10 \mathrm{~min}$ after the UV irradiation was stopped. Furthermore, neither a shift in the diffraction angles nor a new peak was observed, indicating that no new crystalline phase was formed. The trans-to-cis photoisomerization on the surface of crystal could also affect the surface topology, which can be confirmed by AFM data. As shown in Figure 10a,b, the original surface of the 6cazpy crystal was relatively smooth, with an average roughness of $1.03 \mathrm{~nm}$. Upon irradiation with UV light, the surface of the initial crystal became rugged and the roughness increased to $2.39 \mathrm{~nm}$, suggesting that the molecular arrangement became disordered on the short-range length scale in the irradiated areas. Similarly, changes in the PXRD and AFM patterns of complex-I were observed (Figure $9 \mathrm{c}, \mathrm{d}$ ). The intensity of the peak at $2 \theta=9.179^{\circ}$ decreased to $79 \%$ of the original value by irradiation of the UV light, and it returned to $90 \%$ of the original value after the irradiation was stopped. In addition, although a slight shift of $2 \theta$ from $9.179^{\circ}$ to 
$9.202^{\circ}$ was observed, no new peak was observed when irradiation was applied. AFM data showed that the average roughness of the crystal surface of complex-I increased 30\% (Figure 10c,d), indicating that photoisomerization from trans isomers to cis isomers on the crystal surface will result in disorder in the irradiated surface.

\section{$=$ reactant}

(a)

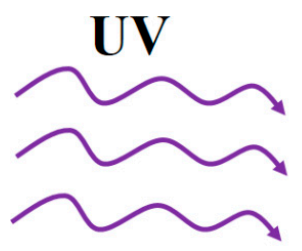



(b)

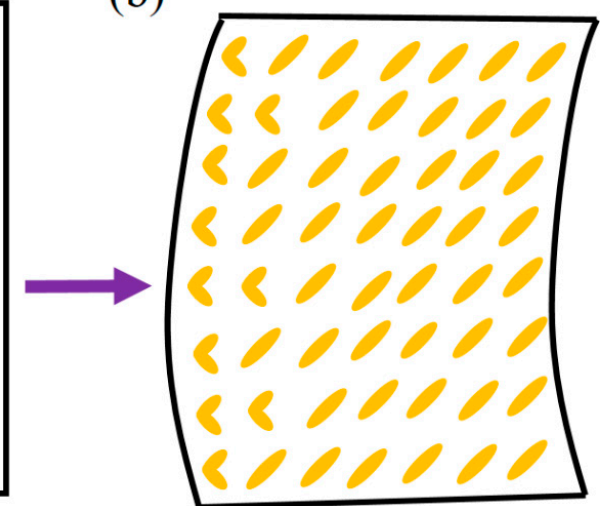

Figure 8. Schematic illustration of the mechanism of photoinduced motion upon irradiation of the UV light. (a) The ordered arrangement of photoactive molecules before UV light irradiation. (b) The incident UV light leads to trans to cis photoisomeriaztion on the crystal surface and the stress between two regions drives the visible deformation of the crystal.

(a)

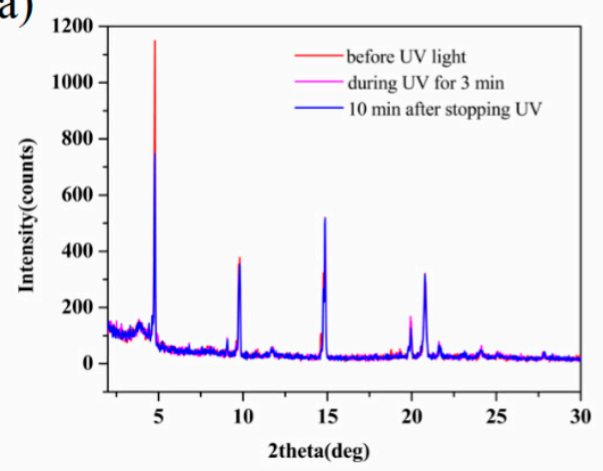

(c)

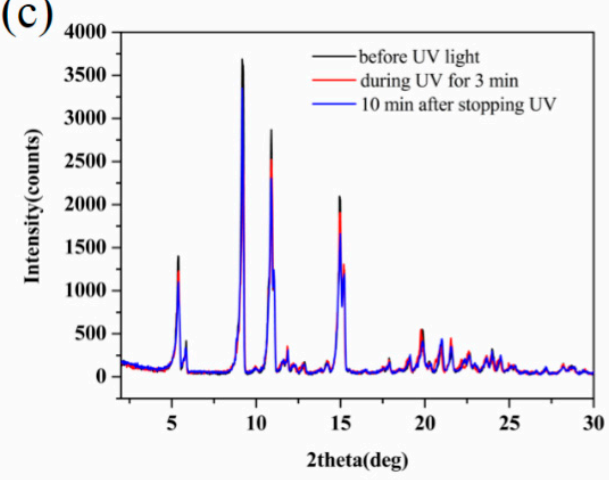

(b)

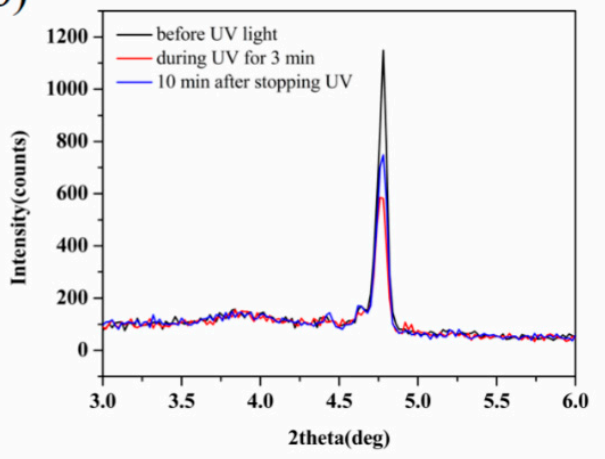

(d)

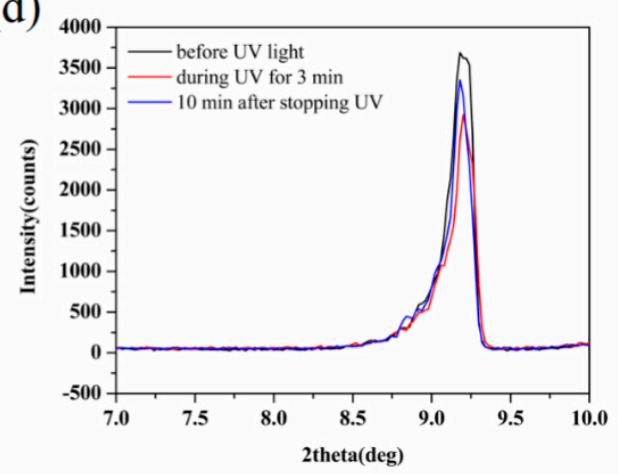

Figure 9. PXRD patterns for (a,b) 6cazpy crystal and (c,d) complex-I crystal before, during and after UV irradiation. (b) The peak at $2 \theta=4.782^{\circ}$ of 6 cazpy, (d) $2 \theta=9.179^{\circ}$ of complex-I crystals before, during and after UV irradiation. 


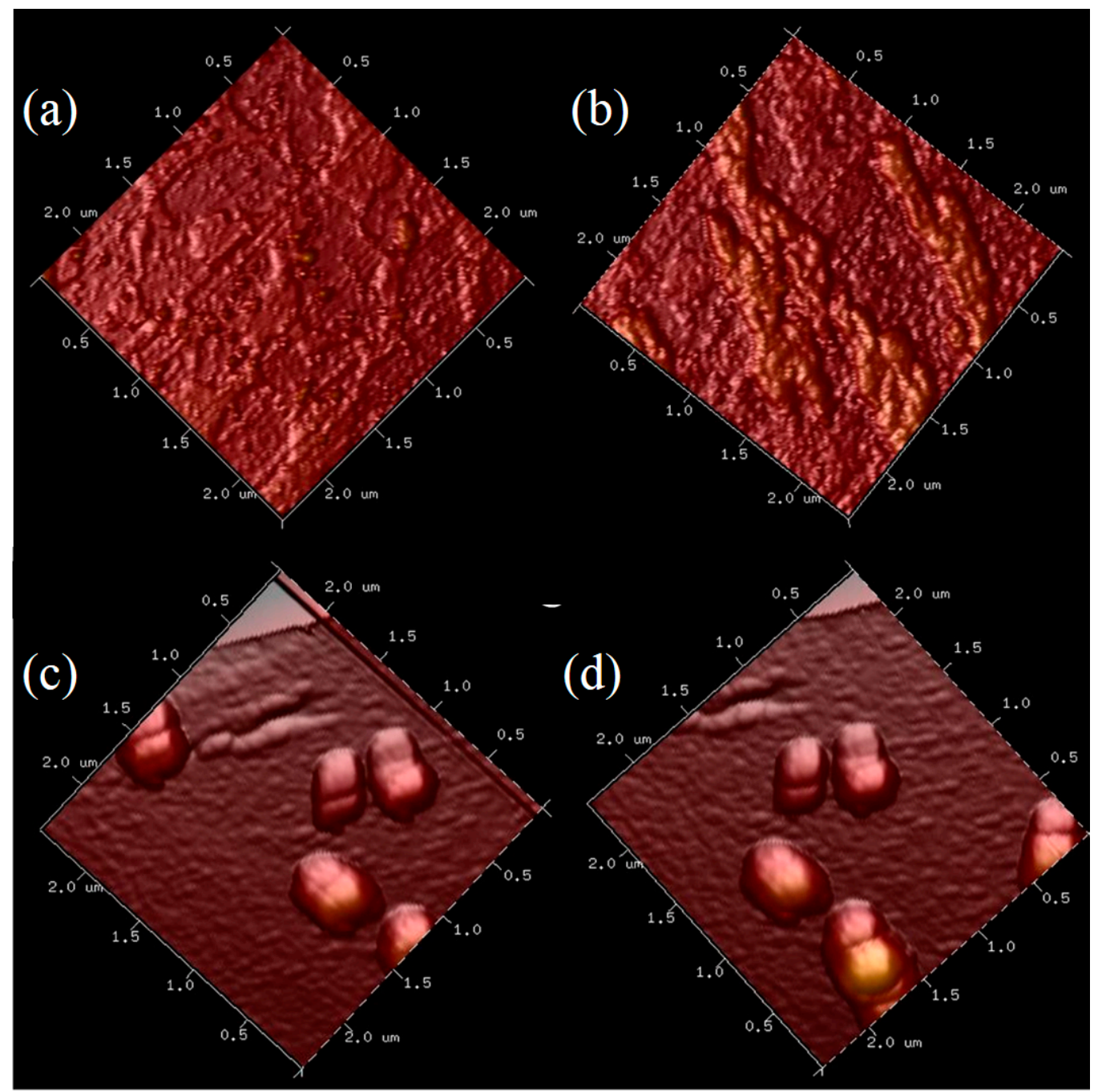

Figure 10. AFM images of the surfaces of 6cazpy crystal and complex-I crystal before (a,c) and during $(\mathbf{b}, \mathbf{d})$ UV irradiation.

\section{Conclusions}

In this work, plate-like 6cazpy crystals and needle-like $\left(\mathrm{Zn}(\mathrm{acac})_{2}\right)(6 \mathrm{cazpy})_{2}$ crystals were successfully synthesized and fabricated. UV/Vis spectra of 6cazpy and complex-I in toluene solution at four irradiation conditions were measured to explore the photoisomerization of azopyridne molecules. It was found that the change of the absorbance peak exponentially increased with exposure time or light intensity and the photoisomerization exhibited first-order kinetics. Upon UV irradiation, plate-like crystals bent away from the light source due to the trans-to-cis photoisomerization of azopyridine derivatives in the crystalline phase. In addition, needle-like complex-I crystal with a thickness of $44 \mu \mathrm{m}$ can also bend upon UV irradiation and can return immediately after the UV light was stopped. By analyzing the PXRD and AFM data, the structural changes in molecules and the surface topology changes upon photoisomerization were also investigated. The mechanism of photoisomerization was proposed.

Supplementary Materials: The following are available online at http://www.mdpi.com/2073-4352/10/2/92/s1, Figures S1 and S3: 1HNMR spectra, Figures S2 and S4: FTIR spectra, Figure S5a-d: UV/Vis absorption spectra of complex-I in toluene, Figure S5e-h: Plots of change of absorbance peak formed with time or light intensity, Videos S1-S4: Reversible bending motion of plate-like 6cazpy crystals, Video S5: Reversible bending of a needle-like crystal of complex-I. 
Author Contributions: Conceptualization, H.H.; Formal analysis, Y.G. and Y.H.; Funding acquisition, H.H.; Investigation, Y.G., Y.H., and L.G.; Methodology, Y.G., Y.H., and H.H.; Project administration, H.H.; Supervision, H.H.; Validation, Y.G.; Visualization, Y.G.; Writing—original draft, Y.G.; Writing—review \& editing, Y.G., Y.H., L.G., and H.H. All authors have read and agreed to the published version of the manuscript.

Funding: This research is financially supported by Major National Scientific Instrument Development Project (No.21527812).

Conflicts of Interest: The authors declare no conflict of interest.

\section{References}

1. Feinberg, A.W.; Feigel, A.; Shevkoplyas, S.S.; Sheehy, S.; Whitesides, G.M.; Parker, K.K. Muscular thin films for building actuators and powering devices. Science 2007, 317, 1366-1370. [CrossRef] [PubMed]

2. Yu, H. Recent advances in photoresponsive liquid-Crystalline polymers containing azobenzene chromophores. J. Mater. Chem. C 2014, 2, 3047-3054. [CrossRef]

3. Wang, J.; Wang, S.; Zhou, Y.; Wang, X.; He, Y. Fast Photoinduced Large Deformation of Colloidal Spheres from a Novel 4-Arm Azobenzene Compound. ACS Appl. Mater. Interfaces 2015, 7, 16889. [CrossRef] [PubMed]

4. Seki, T. Light-Directed alignment, surface morphing and related processes: Recent trends. J. Mater. Chem. C 2016, 4. [CrossRef]

5. Miaudet, P.; Derré, A.; Maugey, M.; Zakri, C.; Piccione, P.M.; Inoubli, R.; Poulin, P. Shape and temperature memory of nanocomposites with broadened glass transition. Science 2007, 318, 1294-1296. [CrossRef] [PubMed]

6. Zhang, X.; Pint, C.L.; Lee, M.H.; Schubert, B.E.; Jamshidi, A.; Takei, K.; Ko, H.; Gillies, A.; Bardhan, R.; Urban, J.J. Optically- and thermally-Responsive programmable materials based on carbon nanotube-Hydrogel polymer composites. Nano Lett. 2011, 11, 3239-3244. [CrossRef]

7. Harris, K.D.; Bastiaansen, C.W.; Lub, J.; Broer, D.J. Self-Assembled polymer films for controlled agent-Driven motion. Nano Lett. 2005, 5, 1857. [CrossRef]

8. Osada, Y.; Okuzaki, H.; Hori, H. A polymer gel with electrically driven motility. Nature 1992, 355, $242-244$. [CrossRef]

9. Bellin, I.; Kelch, S.; Langer, R.; Lendlein, A. Polymeric triple-Shape materials. Proc. Natl. Acad. Sci. USA 2006, 103, 18043-18047. [CrossRef]

10. Nath, N.K.; Panda, M.K.; Sahoo, S.C.; Naumov, P. Thermally Induced and Photoinduced Mechanical Effects in Molecular Single Crystals-A Revival. Crystengcomm 2014, 16, 1850-1858. [CrossRef]

11. Koshima, H.; Ojima, N.; Uchimoto, H. Mechanical motion of azobenzene crystals upon photoirradiation. J. Am. Chem. Soc. 2009, 131, 6890-6891. [CrossRef] [PubMed]

12. Koshima, H.; Ojima, N. Photomechanical bending of 4-Aminoazobenzene Crystals. Dye Pigment. 2012, 92, 798-801. [CrossRef]

13. Bushuyev, O.S.; Singleton, T.A.; Barrett, C.J. Fast, Reversible, and General Photomechanical Motion in Single Crystals of Various Azo Compounds Using Visible Light. Adv. Mater. 2013, 25, 1796-1800. [CrossRef] [PubMed]

14. Bushuyev, O.S.; Tomberg, A.; Friščić, T.; Barrett, C.J. Shaping crystals with light: Crystal-To-Crystal isomerization and photomechanical effect in fluorinated azobenzenes. J. Am. Chem. Soc. 2013, 135, 12556-12559. [CrossRef]

15. Bushuyev, O.S.; Corkery, T.C.; Barrett, C.J.; Friščić, T. Photo-Mechanical azobenzene cocrystals and in situ X-Ray diffraction monitoring of their optically-Induced crystal-To-Crystal isomerisation. Chem. Sci. 2014, 5, 3158-3164. [CrossRef]

16. Koshima, H.; Takechi, K.; Uchimoto, H.; Shiro, M.; Hashizume, D. Photomechanical bending of salicylideneaniline crystals. Chem. Commun. 2011, 47, 11423-11425. [CrossRef]

17. Kuroki, L.; Takami, S.; Yoza, K.; Morimoto, M.; Irie, M. Photoinduced shape changes of diarylethene single crystals: Correlation between shape changes and molecular packing. Photochem. Photobiol. Sci. 2010, 9, 221-225. [CrossRef]

18. Terao, F.; Morimoto, M.; Irie, M. Light-Driven molecular-Crystal actuators: Rapid and reversible bending of rodlike mixed crystals of diarylethene derivatives. Angew. Chem. Int. Ed. 2012, 51, 901-904. [CrossRef] 
19. Kitagawa, D.; Kobatake, S. Crystal thickness dependence of the photoinduced crystal bending of 1-(5-methyl2-(4-(p-vinylbenzoyloxymethyl)phenyl)-4-thiazolyl)-2-(5-methyl-2-phenyl-4-thiazolyl)perfluorocyclopentene. Photochem. Photobiol. Sci. Off. J. Eur. Photochem. Assoc. Eur. Soc. Photobiol. 2014, 13, 764-769. [CrossRef]

20. Zhu, L.; Alkaysi, R.O.; Bardeen, C.J. Reversible Photoinduced Twisting of Molecular Crystal Microribbons. J. Am. Chem. Soc. 2011, 133, 12569-12575. [CrossRef]

21. Koshima, H.; Uchimoto, H.; Taniguchi, T.; Nakamura, J.; Asahi, T.; Asahi, T. Mechanical motion of molecular crystals induced by $[4+4]$ photodimerisation. Crystengcomm 2016, 18. [CrossRef]

22. Matsunaga, Y.; Goto, K.; Kubono, K.; Sako, K.; Shinmyozu, T. Photoinduced color change and photomechanical effect of naphthalene diimides bearing alkylamine moieties in the solid state. Chemistry 2014, 20, 7309-7316. [CrossRef] [PubMed]

23. Koshima, H.; Nakaya, H.; Uchimoto, H.; Ojima, N. Photomechanical Motion of Furylfulgide Crystals. Chem. Lett. 2012, 41, 107-109. [CrossRef]

24. Medishetty, R.; Husain, A.; Bai, Z.; Runčevski, T.; Dinnebier, R.E.; Naumov, P.; Vittal, J.J. Single crystals popping under UV light: A photosalient effect triggered by a [2+2] cycloaddition reaction. Angew. Chem. 2014, 53, 5907. [CrossRef] [PubMed]

25. Medishetty, R.; Sahoo, S.C.; Mulijanto, C.E.; Naumov, P.; Vittal, J.J. Photosalient Behavior of Photoreactive Crystals. Chem. Mater. 2015, 27, 1821-1829. [CrossRef]

26. Kitagawa, D.; Nishi, H.; Kobatake, S. Photoinduced Twisting of a Photochromic Diarylethene Crystal. Angew. Chem. 2013, 125, 9320-9322. [CrossRef]

27. Kim, T.; Zhu, L.; Mueller, L.J.; Bardeen, C.J. Mechanism of Photoinduced Bending and Twisting in Crystalline Microneedles and Microribbons Composed of 9-Methylanthracene. J. Am. Chem. Soc. 2014, 136, 6617. [CrossRef]

28. Harris, K.D.; Cuypers, R.; Scheibe, P.; Oosten, C.L.V.; Bastiaansen, C.W.M.; Lub, J.; Broer, D.J. Large amplitude light-induced motion in high elastic modulus polymer actuators. J. Mater. Chem. 2005, 15, 5043-5048. [CrossRef]

29. Liu, Z.; Tang, R.; Xu, D.; Liu, J.; Yu, H. Precise Actuation of Bilayer Photomechanical Films Coated with Molecular Azobenzene Chromophores. Macromol. Rapid Commun. 2015, 36, 1171. [CrossRef]

30. Al-Kaysi, R.O.; Bardeen, C.J. Reversible Photoinduced Shape Changes of Crystalline Organic Nanorods. Adv. Mater. 2007, 19, 1276-1280. [CrossRef]

31. Taniguchi, T.; Fujisawa, J.; Shiro, M.; Koshima, H.; Asahi, T. Mechanical Motion of Chiral Azobenzene Crystals with Twisting upon Photoirradiation. Chemistry 2016, 22, 7950. [CrossRef]

32. Segarra-Maset, M.D.; Leeuwen, P.W.N.M.V.; Freixa, Z. Light Switches the Ligand! Photochromic Azobenzene-Phosphanes. Eur. J. Inorg. Chem. 2010, 2010, 2075-2078. [CrossRef]

33. Chen, Y.; Yu, H.; Quan, M.; Zhang, L.; Yang, H.; Lu, Y. Photothermal effect of azopyridine compounds and their applications. Rsc Adv. 2014, 5, 4675-4680. [CrossRef]

34. Chen, Y.; Yu, H.; Zhang, L.; Yang, H.; Lu, Y. Photoresponsive liquid crystals based on halogen bonding of azopyridines. Chem. Commun. 2014, 50, 9647-9649. [CrossRef] [PubMed]

35. Chen, Y.; Quan, M.; Yu, H.; Zhang, L.; Yang, H.; Lu, Y. Fabrication of nanofibres with azopyridine compounds in various acids and solvents. Rsc Adv. 2015, 5, 31219-31225. [CrossRef]

36. Cui, L.; Zhao, Y. Azopyridine Side Chain Polymers: An Efficient Way To Prepare Photoactive Liquid Crystalline Materials through Self-Assembly. Chem. Mater. 2004, 16, 2076-2082. [CrossRef]

37. Pladzyk, A.; Ponikiewski, Ł.; Dołęga, A.; Słowy, K.; Sokołowska, A.; Dziubińska, K.; Hnatejko, Z. Structural Variety of Cobalt(II), Nickel(II), Zinc(II), and Cadmium(II) Complexes with 4,4'-Azopyridine: Synthesis, Structure and Luminescence Properties. Chem.-Asian J. 2015, 10, 2388-2396. [CrossRef]

38. Aoki, K.I.; Masaru Nakagawa, A.; Ichimura, K. Self-Assembly of Amphoteric Azopyridine Carboxylic Acids: Organized Structures and Macroscopic Organized Morphology Influenced by Heat, pH Change, and Light. J. Am. Chem. Soc. 2006, 122, 10997-11004. [CrossRef]

39. Kobatake, S.; Takami, S.; Muto, H.; Ishikawa, T.; Irie, M. Rapid and reversible shape changes of molecular crystals on photoirradiation. Nature 2007, 446, 778-781. [CrossRef]

40. Panda, M.K.; Ghosh, S.; Yasuda, N.; Moriwaki, T.; Mukherjee, G.D.; Reddy, C.M.; Naumov, P. Spatially resolved analysis of short-range structure perturbations in a plastically bent molecular crystal. Nat. Chem. 2015, 7, 65-72. [CrossRef] 
41. Naumov, P.; Chizhik, S.; Panda, M.K.; Nath, N.K.; Boldyreva, E. Mechanically Responsive Molecular Crystals. Chem. Rev. 2015, 115, 12440. [CrossRef] [PubMed]

42. Henrio, F. Use of Monohydrate Zinc Acetylacetonate as Halogenated Polymer Stabilizer and Preparation Method. U.S. Patent Application No. US6448314B1, 10 September 2002.

43. Pastusiak, M.; Dobrzynski, P.; Kaczmarczyk, B.; Kasperczyk, J.; Smola, A. The polymerization mechanism of lactide initiated with zinc (II) acetylacetonate monohydrate. Polymer 2011, 52, 5255-5261. [CrossRef]

44. Taguchi, Y.; Shiobara, T. Resin Composition, Reflector for Light-Emitting Semiconductor Device, and Light-Emitting Semiconductor Unit. U.S. Patent Application No. US8455899B2, 4 June 2013.

45. Goossens, T.P.A.; Vrielynck, F.A.C.; Hosten, N.G.C.; Van Aken, K.J.A. Transesterification Process Using Mixed Salt Acetylacetonates Catalysts. U.S. Patent Application No. US8865931B2, 21 October 2014.

46. Kitagawa, D.; Tsujioka, H.; Tong, F.; Dong, X.; Bardeen, C.J.; Kobatake, S. Control of Photomechanical Crystal Twisting by Illumination Direction. Chemistry 2018, 140, 4208-4212. [CrossRef] [PubMed]

47. Kim, T.; Zhu, L.; Alkaysi, R.O.; Bardeen, C.J. Organic photomechanical materials. Chemphyschem 2014, 15, 400-414. [CrossRef] [PubMed]

(C) 2020 by the authors. Licensee MDPI, Basel, Switzerland. This article is an open access article distributed under the terms and conditions of the Creative Commons Attribution (CC BY) license (http://creativecommons.org/licenses/by/4.0/). 